\title{
Chronic dysimmune demyelinating polyneuropathy: a clinical and electrophysiological study of 93 patients
}

Thierry Maisonobe, Benedicte Chassande, Marc Vérin, Mouti Jouni, Jean-Marc Léger, Pierre Bouche

\begin{abstract}
Objectives-To identify clinical, electrophysiological, and immunological characteristics of chronic immune demyelinating polyneuropathy to define for each group the appropriate therapeutic strategies.
\end{abstract}

Methods-The clinical and electrophysiological data and the response to treatment of 93 patients with an acquired chronic dysimmune demyelinating polyneuropathy (CDDP) studied over a period of 10 years were reviewed. Two groups were identified: group 1, comprising 64 patients with an idiopathic CDDP, of whom 13 had serum monoclonal or polyclonal gammopathy without detectable antibodies directed against the "myelin associated glycoprotein" (MAG), and group 2, comprising 29 patients with an IgM monoclonal gammopathy of undetermined significance (MGUS) with antibodies binding to the MAG.

Results-Group 1 patients had either a progressive or relapsing course. The relapsing course had more pronounced distal slowing of motor conduction velocity. In group 1, there were no significant clinical or electrophysiological differences between patients with or without gammopathy. Patients with anti-MAG antibody (group 2) differed significantly from group 1 patients, especially on the basis of electrophysiological results. They had a more pronounced slowing of peroneal motor nerve conduction velocity, a lower frequency of conduction block, and a distal accentuation of conduction slowing, distinguishing them from those with idiopathic CDDP, Charcot-Marie-Tooth polyneuropathy type $1 \mathrm{~A}$, and control subjects.

Conclusion-The idiopathic CDDP group is heterogeneous with probably different subgroups. Patients with IgM MGUS polyneuropathy and anti-MAG antibodies have characteristics which distinguish them significantly from other CDDP and suggest different immune mechanisms and responses to treatment.

(F Neurol Neurosurg Psychiatry 1996;61:36-42)

Keywords: demyelinating polyneuropathy; conduction block; monoclonal gammopathy; antimyelin associated glycoprotein antibodies
Most of the acquired chronic demyelinating polyneuropathies seem to result from an immunological conflict. Although the underlying cause and pathogenetic mechanisms are not well understood, immune processes may play a part in chronic inflammatory demyelinating polyradiculoneuropathy (CIDP)..$^{1-3}$ Serum immunoglobulin abnormalities are found in some patients with chronic demyelinating polyneuropathy. ${ }^{48}$ Among them, an IgM monoclonal gammopathy of undetermined significance (MGUS) with a serum activity directed against the "myelin associated glycoprotein" (MAG) has been found. ${ }^{910}$ In these patients there is evidence to suggest that the anti-MAG antibodies are pathogenic. ${ }^{11}{ }^{13}$ The presence of an MGUS has been reported to modify the presentation, features, and response to treatment of patients with chronic demyelinating polyneuropathy.$^{814}{ }^{19}$ We report here the results of clinical and electrophysiological findings in a series of 93 patients with chronic dysimmune demyelinating polyneuropathy (CDDP): 64 with an idiopathic CIDP and 29 with an IgM MGUS and anti-MAG antibody demyelinating polyneuropathy.

\section{Patients and methods}

\section{PATIENTS}

We made a retrospective study of patients evaluated in the neurophysiological department of the Salpêtrière hospital over a 10 year period (1985-94). Patients were included on the basis of previously described diagnostic CIDP criteria. ${ }^{1520-23}$ They presented a peripheral neuropathy with a progression of weakness or sensory symptoms in at least two limbs for more than a month. The sensory or motor deficit did not improve or worsen during the six months after onset and the disease was not recurrent. Demyelinating neuropathy was diagnosed at the time of the initial electrophysiological examination. All patients had undergone a comprehensive evaluation at the time of diagnosis to rule out other causes of neuropathy, such as diabetes mellitus, drugs and heavy metal intoxication, vitamin deficiency, uraemia, alcoholism, collagen vascular disease, and malignancy.

A nerve biopsy was performed on 57 patients to confirm the diagnosis and to exclude patients with vasculitis and other evidence of specific disease. The pattern of demyelination and remyelination, the degree of axonal damage, and inflammation are the subject of an ongoing study. 
Patients with a benign IgM IgG or IgA monoclonal gammopathy were included. Patients with a paraproteinaemic polyneuropathy and plasmocytoma or osteoclastic myeloma were excluded, as were those with a POEMS syndrome.

Patients with a pure motor multifocal neuropathy with persistent conduction block were not included in this study, and have been reported elsewhere. ${ }^{24}$

\section{CLINICAL ASSESSMENT}

The patient's clinical disability was graded according to the following criteria: (1) mild motor or sensory symptoms and signs; (2) moderate motor or sensory involvement; (3) severe involvement requiring assistance for eating, dressing, or walking.

\section{ELECTRODIAGNOSTIC EXAMINATIONS}

Needle EMG examination was performed in all patients. Although the recruitment pattern, amplitude, form, and duration of motor unit potentials were evaluated, we used only the presence or absence of fibrillation potentials. A motor nerve conduction study of the median, ulnar, and peroneal nerves was performed. Compound muscle action potential (CMAP) amplitudes, conduction velocities, distal latencies, $F$ wave latencies, and proxi$\mathrm{mal} /$ distal amplitude ratios were reviewed. A conduction block was defined as a reduction of more than $50 \%$ of the proximal:distal amplitude ratio at Erb's point and more than $30 \%$ elsewhere. However, a reduction of the CMAP amplitude was considered to be due to temporal dispersion if the duration of CMAP was $15 \%$ greater after proximal stimulation when compared with the distal CMAP. A minimum of 10 consecutive distal $F$ waves were elicited for each nerve, and the minimal $\mathrm{F}$ wave latency was measured. Median, ulnar, sural, and superficial peroneal sensory nerve action potentials were recorded, and peak to peak amplitude and conduction velocity were measured. The terminal latency index (TLI; distal conduction distance in $\mathrm{mm} /$ proximal conduction velocity in $\mathrm{m} / \mathrm{s} /$ distal motor latency in ms) was used to compare distal and proximal segment conduction velocity. ${ }^{1625}$ Distal conduction distances, between the recording electrode over the motor point and the site of distal nerve stimulation, were $60 \mathrm{~mm}$ for the median and ulnar nerves and $90 \mathrm{~mm}$ for the peroneal nerve.

The electrophysiological criteria defined by the American Academy of Neurology ad hoc subcommittee $^{26}$ for the diagnosis of chronic demyelinating polyneuropathies were applied and evaluated in our patients.

\section{LABORATORY STUDIES}

All patients were studied with serum immunoelectrophoresis. Malignant plasma cell dyscrasia was ruled out by bone marrow examination and radiological skeletal study. Anti-MAG activity was studied by immunoblotting in all patients with IgM MGUS. When more than one CSF examination was performed the results of the initial study were retained.
Regular biological investigations with conventional biological assays, thyroid function, HIV, and hepatitis serology were performed.

Magnetic resonance imaging was performed only in patients with clinical involvement of the CNS.

\section{TREATMENT}

During the decade of the study, most patients with the progressive and recurrent form of CDDP and those with MGUS without MAG were initially treated by corticosteroids and plasma exchange. When the response was poor, treatment by immunosuppressive drugs was undertaken. In recent years, some patients have initially been treated by intravenous human immunoglobulin (IVIg). Most of the patients with MGUS and anti-MAG antibody were treated by immunosuppressive drugs associated in some cases with plasma exchange or IVIg. A favourable outcome after treatment was defined as a gain of one grade on the clinical functional scale.

\section{STATISTICAL METHODS}

Mean values were compared by analysis of variance (ANOVA). Differences between groups were regarded as significant at a level of $\mathbf{P}<0.05$ using the Scheffer $F$ test. The $\chi^{2}$ test was used for the analysis of categorical data.

\section{Results \\ DESCRIPTIVE DATA}

Ninety three patients ( 54 male and 39 female) with CDDP were diagnosed during the 10 year study period (1985-94). Most of them had a neuropathy of more than two months, and the progression of the involvement was at least six months. An infectious event preceding the peripheral neuropathy was found in three patients. In one patient, relapses were associated with pregnancy. The 93 patients were classified into two groups, depending on the presence or absence of serum anti-MAG antibodies: group 1, comprising 64 patients, included those with MGUS but no anti-MAG activity and group 2 comprising 29 patients with a progressive or recurrent polyneuropathy associated with IgM MGUS and serum antiMAG activity.

\section{GROUP 1 PATIENTS}

\section{Clinical study (table 1)}

Mean age at onset was 48.3 (SD 18.5) years (range 11-86 years). The sex ratio was $1 \cdot 3$ male: 1 female. In six patients $(9 \cdot 3 \%)$ there was a rapid onset of the neuropathy followed by a progressive phase lasting from four to 12 weeks. Fifty four patients ( $86 \%$ ) had a sensory-motor polyneuropathy, of which 45 $(72 \%)$ had a predominantly motor neuropathy and nine $(14 \%)$ a predominantly sensory neuropathy. Seven patients (11\%) had only sensory symptoms and signs and two had only motor signs. Generalised areflexia was seen in $67.5 \%$ of patients, and areflexia limited to the lower limbs was found in $20 \%$. Cranial nerve involvement was found in 15 patients 
Table 1 Main clinical characteristics: comparison of CDDP (group 1) and anti-MAG IgM CDDP (group 2)

\begin{tabular}{llll}
\hline & $\begin{array}{l}C D D P \\
(n=64)\end{array}$ & $\begin{array}{l}\text { anti-MAG IgM } \\
C D D P(n=29)\end{array}$ & P value \\
\hline Sex ratio (M/F) & $1 \cdot 3 / 1$ & $1 \cdot 6 / 1$ & NS \\
Age at onset (y) (mean (SD)) & $48.3(18 \cdot 5)$ & $63.7(11 \cdot 4)$ & 0.0001 \\
Patients with relapses (\%) & 29.6 & $6 \cdot 8$ & 0.014 \\
Clinical features (\%): & 3 & 0 & - \\
$\quad$ Only motor & 11 & 38 & - \\
Only sensory & 72 & 14 & - \\
Motor > sensory & 14 & 48 & 0.004 \\
Sensory > motor & 23.4 & 0 & \\
Cranial nerves (\%) & & & \\
\hline
\end{tabular}

$(23 \cdot 4 \%)$. Facial weakness was found in three patients, bulbar involvement in one, and external ophtalmoplegia with diplopia in five. Tongue and peribuccal paraesthesia occurred in six patients. Dysautonomia and respiratory failure occurred in only two patients, both of whom had pure motor neuropathy. Three patients had MRI evidence of central demyelination and minor signs of upper motor neuron involvement (Babinski's sign). For overall functional impairment: disability was mild in $25 \%$, moderate in $60 \%$, and severe in $15 \%$. Nineteen $(29.6 \%)$ patients had a relapsing course. Relapse was defined as a worsening of symptoms or signs resulting in an increase in disability of one or more grades on the disability scale, with a subsequent improvement, without any withdrawal of treatment. The mean number of relapses per year was 0.6 (SD $0 \cdot 4)$.

\section{Electrophysiological characteristics}

Values for motor nerve conduction velocity (MNCV) and minimal distal latency (MDL)

Table 2 Motor nerve conduction studies: comparison of CDDP (group 1) and anti-MAG IgM CDDP (group 2)

\begin{tabular}{|c|c|c|c|}
\hline Nerve & $\begin{array}{l}C D D P \\
(n=64)\end{array}$ & $\begin{array}{l}\text { anti-MAG IgM } \\
C D D P(n=29)\end{array}$ & $P$ value \\
\hline $\begin{array}{c}\text { Median (n) } \\
\text { MNCV } \\
\text { DL } \\
\text { TLI }\end{array}$ & $\begin{array}{l}61 \\
32 \cdot 5(13 \cdot 8) \\
8 \cdot 0(4 \cdot 9) \\
0 \cdot 36(0 \cdot 23)\end{array}$ & $\begin{array}{l}26 \\
33.8(11.9) \\
9.7(4 \cdot 3) \\
0.22(0.14)\end{array}$ & $\begin{array}{l}- \\
\text { NS } \\
\text { NS } \\
0.008\end{array}$ \\
\hline $\begin{array}{l}\text { Ulnar (n) } \\
\text { MNCV } \\
\text { DL } \\
\text { TLI }\end{array}$ & $\begin{array}{l}61 \\
30 \cdot 7(11 \cdot 9) \\
5.9(4 \cdot 3) \\
0.46(0 \cdot 21)\end{array}$ & $\begin{array}{l}27 \\
31.0(10.4) \\
6.6(3.2) \\
0.35(0.08)\end{array}$ & $\begin{array}{l}\overline{ } \\
\text { NS } \\
\text { NS } \\
0 \cdot 010\end{array}$ \\
\hline $\begin{array}{l}\text { Peroneal (n) } \\
\text { MNCV } \\
\text { DL } \\
\text { TLI }\end{array}$ & $\begin{array}{l}55 \\
28 \cdot 5(10 \cdot 1) \\
10.5(8 \cdot 0) \\
0.43(0 \cdot 19)\end{array}$ & $\begin{array}{l}23 \\
20.0(6 \cdot 1) \\
13.9(6 \cdot 3) \\
0.38(0 \cdot 12)\end{array}$ & $\begin{array}{l}- \\
0 \cdot 020 \\
\text { NS } \\
\text { NS }\end{array}$ \\
\hline
\end{tabular}

Values are means (SD); $\mathrm{MNCV}=$ motor nerve conduction velocity $(\mathrm{m} / \mathrm{s}) ; \mathrm{DL}=$ dista latency $(\mathrm{ms})$; TLI = terminal latency index.

Table 3 Other electrophysiological studies: comparison of CDDP (group 1) and anti-MAG IgM CDDP (group 2)

\begin{tabular}{|c|c|c|c|}
\hline & $\begin{array}{l}C D D P \\
(n=64)\end{array}$ & $\begin{array}{l}\text { anti-MAG IgM } \\
C D D P(n=29)\end{array}$ & Pvalue \\
\hline $\begin{array}{l}\text { Absent or prolonged } F \\
\text { Upper limb } \\
\text { Lower limb }\end{array}$ & $\begin{array}{l}85 \\
60\end{array}$ & $\begin{array}{l}91 \cdot 7 \\
90\end{array}$ & $\begin{array}{l}\text { NS } \\
\text { NS }\end{array}$ \\
\hline Conduction block $\dagger$ & 53 & $14 \cdot 3$ & 0.001 \\
\hline Temporal dispersion $\nmid$ & 59 & $57 \cdot 1$ & NS \\
\hline $\begin{array}{l}\text { Conduction block or } \\
\text { temporal dispersion } f\end{array}$ & 89 & $64 \cdot 3$ & $0 \cdot 012$ \\
\hline $\begin{array}{l}\text { Abnormal sensory pote } \\
\text { Upper limb } \\
\text { Lower limb }\end{array}$ & $\begin{array}{l}83 \\
78\end{array}$ & $\begin{array}{l}100 \\
100\end{array}$ & $\begin{array}{l}0.020 \\
0.007\end{array}$ \\
\hline Fibrillation potentials & 23 & 20 & NS \\
\hline
\end{tabular}

Values are \% patients; $\star_{\text {in }}$ at least two nerves; tin one or more motor nerves. disclosed a demyelinating process (table 2). Temporal dispersion of the CMAP or conduction block were present in one or more motor nerves in $89 \%$ of patients. $F$ waves were absent or their minimal latency was often increased. Fibrillation potentials or positive sharp waves were found in $23 \%$ of patients (table 3).

Terminal latency index was determined in 181 normal subjects (controls) for the median nerve $(0.34$ (SD 0.04)), ulnar nerve $(0.43$ (SD $0.07)$ ), and peroneal nerve $(0.48$ (SD 0.07)). In CDDP, mean TLI did not differ significantly from controls, but there was considerable heterogeneity. Three patterns were found: (1) low TLI values (distal conduction was very much more reduced in comparison to proximal conduction); (2) values comparable with those of controls (distal conduction identical to proximal conduction); (3) high values (proximal conduction lower than distal conduction).

\section{Biological study}

Examination of CSF was performed in 51 patients $(79 \%)$, most of whom were found to have high protein concentrations: $94.1 \%$ in relapsing CDDP (mean $=1 \cdot 18(\mathrm{SD} 0 \cdot 89) \mathrm{g} / \mathrm{l})$ and $90.9 \%$ in progressive CDDP (mean = $1.06(\mathrm{SD} 0.57) \mathrm{g} / \mathrm{l})$. All CSF analyses disclosed a normal cell count.

In group 1, 12 patients had IgM MGUS without anti-MAG activity, one had IgG MGUS, four had a polyclonal gammopathy, of whom three had IgM and one IgG. The other 47 patients had normal immunoelectrophoresis results. Nine patients initially had no evidence of a monoclonal gammopathy but subsequently developed a MGUS. The mean delay was four years (range seven months to nine years); in four of nine patients, the gammopathy was initially polyclonal over a period of many months or several years. In these patients, malignant plasma cell dyscrasias were exluded by radiological skeletal surveys and by haematological evaluations, which included a bone marrow examination. There were no differences in presentation, initial clinical course, or initial electrodiagnostic features which could be used to distinguish patients with CDDP with delayed MGUS from the other patients with CDDP.

The follow up study showed that three patients had subsequently developed associated systemic conditions in addition to CDDP (none at the time of diagnosis): one chronic active hepatitis, one non-Hodgkin's malignant lymphoma, and one solid cancer (ovarian). These occurred two, six, and four years, respectively, after the polyneuropathy was diagnosed. These patients could not be distinguished from the other patients with CDDP, either clinically or electrophysiologically or in terms of the subsequent course of the neuropathy.

\section{Treatment and evolution}

Forty patients $(68.5 \%)$ were treated. In those with the progressive form, the initial treatment was oral prednisone $(60 \mathrm{mg} /$ day $)$ in $89.6 \%$ of 
patients. Most of the patients (93\%) experienced no improvement or only marginal improvement with initial treatment. Three received secondary treatment with azathioprine, two with cyclophosphamide, four with cyclosporine and 13 with intravenous IVIg. A favourable response occurred in only $41.8 \%$ of treated patients. In the relapsing form, 15 of $19(79 \%)$ patients were treated: seven with prednisone alone and four with additional plasma exchanges. Four patients received IVIg. Improvement after treatment occurred in $86.6 \%$. Twenty patients were not treated (23.5\%): four with relapsing CDDP and 16 with progressive CDDP. Of those not treated, 10 improved spontaneously, four were stable, and eight worsened. Neither age, clinical course, MNCV, CMAP, nor CSF protein concentration were predictive of the clinical outcome. Only the presence of conduction block and the correspondence of electrophysiological criteria with that of the ad hoc subcommittee ${ }^{26}$ showed a significant correlation with a favourable clinical course.

Comparison of progressive and relapsing CDDP Mean age at onset was significantly lower in patients with relapsing CDDP compared with the progressive form $(41.3$ (SD 16.4) $v 51.2$ (SD 18.6) years). The clinical presentation was not significantly different, but none of the patients had predominant sensory neuropathy; cranial nerve involvement was more frequent in the relapsing subgroup than in the progressive subgroup (36.9\% $v 17 \cdot 8 \%)$. In the relapsing subgroup, proximal weakness was also more frequent. Impairment of overall function was similar. In the relapsing subgroup, motor nerve distal conduction was more severely affected (table 4) and temporal dispersion occurred more often $(P=0.031)$. Patients with relapsing CDDP therefore fulfilled more closely the electrophysiological criteria of the ad hoc subcommittee ${ }^{26} \quad(P=0.043)$. The relapsing patients were more responsive to treatment, especially by corticosteroids.

\section{GROUP 2 PATIENTS}

Clinical presentation was mainly sensory. A generalised areflexia was found in nearly two thirds of the patients. The course was usually progressive without subacute onset. No clinical CNS involvement was found.

Distal motor latencies seemed to be disproportionately increased for the degree of proxi-

Table 4 Motor nerve conduction studies of CDDP without anti-MAG antibodies (group 1): comparison of patients with progressive and relapsing course

\begin{tabular}{|c|c|c|c|}
\hline Nerve & $\begin{array}{l}\text { Progressive } C D D P \\
(n=45)\end{array}$ & $\begin{array}{l}\text { Relapsing CDDP } \\
(n=19)\end{array}$ & $P$ value \\
\hline $\begin{array}{l}\text { Median (n) } \\
\text { MNCV } \\
\text { DL }\end{array}$ & $\begin{array}{l}42 \\
34 \cdot 6(13 \cdot 8) \\
6 \cdot 6(3 \cdot 4)\end{array}$ & $\begin{array}{l}19 \\
27 \cdot 6(12 \cdot 5) \\
10 \cdot 7(6 \cdot 4)\end{array}$ & $\begin{array}{l}\overline{N S} \\
0.002\end{array}$ \\
\hline $\begin{array}{l}\text { Ulnar (n) } \\
\text { MNCV } \\
\text { DL }\end{array}$ & $\begin{array}{l}39 \\
33 \cdot 0(11 \cdot 4) \\
4.6(2 \cdot 1)\end{array}$ & $\begin{array}{l}19 \\
26.0(11.9) \\
8.6(6 \cdot 1)\end{array}$ & $\begin{array}{l}- \\
\overline{0.050} \\
0.001\end{array}$ \\
\hline $\begin{array}{l}\text { Peroneal (n) } \\
\text { MNCV } \\
\text { DL }\end{array}$ & $\begin{array}{l}39 \\
29 \cdot 0(10 \cdot 4) \\
8 \cdot 7(4 \cdot 0)\end{array}$ & $\begin{array}{l}16 \\
27 \cdot 4(9 \cdot 7) \\
14 \cdot 8(12 \cdot 6)\end{array}$ & $\begin{array}{l}\overline{N S} \\
0.012\end{array}$ \\
\hline
\end{tabular}

Values are means $(\mathrm{SD}) ; \mathrm{MNCV}=$ motor nerve conduction velocity $(\mathrm{m} / \mathrm{s}) ; \mathrm{DL}=$ distal latency (ms). mal conduction slowing, as reflected by the lower TLI. The mean TLI was significantly lower than mean values in controls for the median, ulnar, and peroneal nerves $(\mathbf{P}=$ 0.0001 ; table 2). Conduction blocks were rare and sensory potentials were always altered (table 3).

The CSF was examined in 22 patients $(75 \cdot 8 \%)$. All had a raised protein concentration with a mean of $1 \cdot 11$ (SD 0.44$) \mathrm{g} / 1$ (range 0.5 to $2 \mathrm{~g} / \mathrm{l})$. Cell count was normal.

Twenty eight $(96.5 \%)$ patients were treated. The most common initial treatment was chlorambucil (23 patients). Sixteen of the 23 experienced no improvement or only marginal improvement and were treated by plasma exchange (15 patients) and/or IVIg (11 patients). We did not note any lasting favourable response with IVIg. Improvement with the first treatment (chlorambucil) occurred in about $33 \%$. Five patients were treated initially with prednisone alone $(1 \mathrm{mg} / \mathrm{kg} /$ day) and none responded.

COMPARISON OF GROUPS 1 AND 2

Clinically, patients from group 2 had a higher age at onset, with a progressive predominantly sensory deficit without cranial nerve involvement (table 1). Sensory potentials were more severely altered in group 2 (table 3 ). Patients with anti-MAG antibodies had a significantly lower incidence of motor nerve conduction block (table 3), a reduced motor conduction velocity in the peroneal nerve (table 2 ), and a higher percentage of unexcited peroneal nerves $(26 v 17 \%)$. The most pronounced disproportionate distal slowing occurred in antiMAG CDDP, with a significantly lower TLI in comparison with CDDP (table 2). A comparison with TLI found in the study of another chronic demyelinating polyneuropathy, including 93 patients with CMT $1 \mathrm{~A}$ (median: 0.34 (SD 0.1); ulnar: 0.50 (0.14); peroneal $0.53($ SD 0.26$)$ ), showed a similar lower value of TLI for group 2 patients $(P=$ 0.0001 median and ulnar nerve; $P=0.017$ peroneal nerve).

Patients with MGUS without anti-MAG activity differed significantly from patients with anti-MAG (peroneal MNCV 30 (SD 12) $\mathrm{m} / \mathrm{s} v 20(6 \cdot 1) \mathrm{m} / \mathrm{s})$ to the same extent as those without MGUS.

\section{CRITERIA FOR PRIMARY DEMYELINATION}

The sensitivity of the electrodiagnostic criteria of the ad hoc subcommittee ${ }^{26}$ allowed the recognition of $79.3 \%$ of group 2 patients and $71.8 \%$ of group 1 patients. In group 1 , the criteria were met by $89.5 \%$ of relapsing CDDP cases (the difference was significant for the progressive CDDP subgroup; $\mathrm{P}=0.04$ ).

\section{Discussion}

Chronic acquired demyelinating polyneuropathies are usually classified as chronic inflammatory demyelinating polyradiculoneuropathy (CIDP), multifocal demyelinating neuropathy with persistent conduction block, and paraproteinaemic demyelinating polyneu- 
ropathy, including the benign monoclonal gammopathy of undetermined significance (MGUS), and other forms associated with solitary plasmocytoma or osteosclerotic myeloma. ${ }^{7}$ Since the first comprehensive report by Dyck et al ${ }^{21}$ criteria for the diagnosis of CIDP have been well documented. ${ }^{16} 20222327-30$ Serum antibodies directed against the myelin associated glycoprotein (MAG) are often found in patients with IgM monoclonal gammopathy and chronic demyelinating polyneuropathy. ${ }^{13}$ There is evidence that the anti-MAG antibodies may be pathogenic and play a part in the demyelinating neuropathy. ${ }^{11} 12$ Patients with MGUS share clinical and electrophysiological features with patients with CIDP, allowing some authors to study them together. ${ }^{20}$ Others have excluded such patients from their series of patients with CIDP. ${ }^{21228}$ We studied 93 patients who fulfilled the criteria for diagnosis of CIDP $1520-232729$ and compared those with idiopathic CIDP and those with IgM MGUS and serum antiMAG activity. Patients with MGUS or polyclonal gammopathy without anti-MAG antibody were included in the idiopathic CIDP group. Criteria for diagnosing patients with CIDP are still controversial, especially those based on an electrodiagnostic study. Because the criteria proposed by the ad hoc subcommittee $^{26}$ are extremely restrictive, we included some patients who did not meet all these electrophysiological criteria but had other (clinical, biological, pathological) typical features of CIDP.

Sixty four patients had CIDP without antiMAG activity. There was a slight male predominance, in accordance with other studies. ${ }^{152022} 28$ Age at onset was identical to that found in the study by Barohn et al ${ }^{20}$ but higher than that found by McCombe et al. ${ }^{22}$ The difference was probably due to our recruitment of adult patients only. The clinical features were similar to those reported previously. ${ }^{150-22} 28$ Patients (15.5\%) with only sensory symptoms were included. They presented a large alteration in motor nerve conduction velocity with conduction block despite an absence of motor deficit. The pure sensory form has been considered as a different entity, ${ }^{2030}$ whereas in the series reported by Dyck et $a l^{21}$ and McCombe et $a l^{22}$ it was included in the CIDP type and represented $6 \%$ of patients. Oh et al ${ }^{31} 32$ reported similar patients with only sensory neuropathy and electrophysiological features of motor demyelination. The motor involvement appeared later in cases of chronic sensory demyelinating polyneuropathy reported by Berger et al. ${ }^{33}$ The cranial nerves were involved in $23.4 \%$ of patients, a slightly higher frequency than that reported in previous series. ${ }^{15} 20$ We did not find papilloedema, which has been reported in other studies, such as that by Dyck et $a l^{21}$ who found it in $7 \%$ of cases. Most of the patients had a progressive onset of disability of more than two months, but six patients had a rapid onset with a progressive phase of four to 12 weeks. These cases could belong to the subacute form described by Hughes et al, ${ }^{34}$ but in our study they did not differ from the more progressive form. Clinical antecedent illnesses preceding the onset of neuropathy were substantially lower than the $32 \%$ reported in another series, ${ }^{22}$ but in our series, serological study was not systematically done. Three patients had clinical signs of upper motor neuron involvement-namely, a Babinski's signand MRI showed demyelinating lesions of the cerebral white matter. Patients with features of multiple sclerosis associated with demyelinating polyneuropathies have been reported. ${ }^{35} 36$ Although MRI has allowed the detection of abnormalities of white matter in patients with CIDP, ${ }^{37}{ }^{38}$ different frequencies of such abnormalities have been reported. ${ }^{39} 40$

Electrophysiological criteria for chronic demyelination have been widely debated. Several workers $2022233041-43$ proposed their own, and the ad hoc subcommittee established electrophysiological criteria for CIDP. ${ }^{26}$ In none of the CIDP series reported since $1991,{ }^{15162844}$ did all patients meet the criteria of the ad hoc subcommittee. The mean motor conduction velocities and distal latencies of median, ulnar, and peroneal nerves in patients with CDDP were comparable with those in reports of other similar large series. ${ }^{1620-22}$ Using the TLI, a more suitable measurement ${ }^{161825}$ for comparing distal and proximal conduction, we found a wide range of values. Three patterns could thus be discerned: patients with reduced proximal conduction velocity and near normal distal conduction; patients with an equivalent level of reduction in distal and proximal segments; and patients with distal conduction more severely reduced than proximal conduction. The pattern of conduction abnormalities was not homogenous in patients with CDDP, in accordance with the findings of van der Meché. ${ }^{45}$ It differs from patients with hereditary chronic demyelinating polyneuropathy CMT 1A type, in whom the reduction of conduction velocity is homogenous and equal in all nerve segments. ${ }^{46}$ In our study, prolonged $\mathrm{F}$ waves occurred in most cases, with a conduction block or temporal dispersion in nearly $90 \%$ of cases, a frequency considerably higher than that reported in other series. ${ }^{20}$ Fibrillation potentials, indicating associated axonal damage, were found in less than $25 \%$ of patients. This was much lower than that reported in other series. ${ }^{20}$

Patients with MGUS without serum antiMAG activity did not differ significantly from other patients without gammopathy and there would therefore seem to be no reason to differentiate between these patients and those without gammopathy.

In the group of patients with CDDP (group 1), $29 \cdot 7 \%$ (19 patients) had relapses, a lower frequency than that reported elsewhere. ${ }^{20-22}$ The difference is probably because we did not consider as relapsing patients those who were dependent on corticoids or had relapses when steroids were discontinued. Apart from the relapses, these patients had some electrophysiological differences compared with progressive cases.

Twenty nine patients had an IgM MGUS 
with serum anti-MAG activity and were compared with patients with CDDP without antiMAG activity. The clinical features and course did not differ from previous reports. ${ }^{564-49}$ However, we found a pronounced difference in the peroneal motor conduction velocity. This was lower in the patients with anti-MAG antibody, as noted by Nobile-Orazio et al. ${ }^{47}$ It was rare to find conduction block in patients with anti-MAG antibodies, although temporal dispersion was equally frequent in both groups. The TLI was very different in the two groups, especially for the median nerve. Distal motor nerve conduction was slower than proximal conduction, to a similar degree to that found in patients reported by Kaku et al..$^{25}$ This pattern was indicative of a length dependent demyelinating neuropathy, which was not the hallmark of patients with CDDP without anti-MAG activity. The patients with antiMAG IgM MGUS were also very different from patients with MGUS without anti-MAG and those with polyclonal gammopathy. Previous reports comparing patients with and without MGUS have failed to detect any significant electrophysiological differences; 61516 they did not, however, distinguish between patients with MGUS and without anti-MAG activity. Other reports have noted differences between IgM and IgG MGUS polyneuropathy, but found no difference between patients with and without anti-MAG activity ${ }^{819}$ We have shown that patients with chronic demyelinating polyneuropathy and anti-MAG antibody differ significantly from other patients with this type of polyneuropathy but without anti-MAG antibodies. Anti-MAG antibodies act, probably with a specific mechanism, on the nerve fibre, and may be related to the level of anti-MAG antibodies, as recently suggested. ${ }^{18}$

In our experience, results of treatment also differ between groups 1 and 2 . In the group of patients without anti-MAG activity (group 1), progressive patients were more resistant to steroids than relapsing patients. Azathioprine, cyclophosphamide, plasma exchange, or IVIg were alternative treatments. A favourable predictive outcome in this group was found in patients with conduction block and in those who met most fully the ad hoc subcommittee's electrophysiological criteria for demyelination. ${ }^{26}$ In the group of patients with IgM MGUS and anti-MAG antibodies (group 2), treatment was initiated with chlorambucil, but a slight improvement was found in only $33 \%$ of patients. Patients treated with prednisone alone or plasma exchange or IVIg did not seem to have a better response.

The range of immune mediated demyelinating polyneuropathies is probably heterogeneous. Several clinical and electrophysiological syndromes can be identified. It is, therefore necessary to measure clinical, electrophysiological, and serum antibody patterns to determine controlled therapeutic trials and the optimal treatment.

\footnotetext{
1 Lopate G, Pestronk A. Chronic immune demyelinating neuropathies. Semin Neurol 1994;14:131-6.
} 2 van der Meché FGA, van Doorn PA. Guillain-Barré syndrome and chronic inflammatory demyelinating polyneuropathy: immune mechanisms and update on current therapies. Ann Neurol 1995;37(suppl 1): S14-S31.

3 Kornberg AJ, Pestronk A. Immune-mediated neuropathies. Curr Opin Neurol 1993;6:681-7.

4 Donofrio PD, Kelly JJ. Peripheral neuropathy in monoclonal gammopathy of undetermined significance. Muscle Nerve 1989;12:1-8.

5 Notermans NC, Wokke JHJ, Lokhorst HM, Franssen H, van der Graaf Y, Jennekens FGI. Polyneuropathy associated with monoclonal gammopathy of undetermined significance. A prospective study of the pronostic value of nificance. A prospective study of the pronostic value of
clinical and laboratory abnormalities. Brain 1994;117: clinical and

6 Yeung KB, Thomas PK, King RHM, et al. The clinical spectrum of peripheral neuropathies associated with benign monoclonal IgM, IgG and IgA paraproteinaemia. Comparative clinical, immunological and nerve biopsy findings. $\mathcal{F}$ Neurol 1991;238:383-91.

7 Feasby TE. Inflammatory demyelinating polyneuropathy. Neurol Clin 1992;10:651-71.

8 Gosselin S, Kyle RA, Dyck PJ. Neuropathy associated with monoclonal gammopathies of undetermined significance. Ann Neurol 1991;30:54-61.

9 Hafier DA, Johnson D, Kelly JJ, Panitch H, Kyle R, Weiner HL. Monoclonal gammopathy and neuropathy: myelinassociated glycoprotein reactivity and clinical characterisassociated glycoprotein reactivity
tics. Neurology 1986;36:75-8.

10 Nobile-Orazio E, Manfredini E, Carpo M, et al. Frequency and clinical correlates of anti-neural IgM antibodies in neuropathy associated with IgM monoclonal gammopathy. Ann Neurol 1994;36:416-24.

11 Braun PE, Frail DE, Latov N. Myelin-associated glycoprotein is the antigen for a monoclonal IgM in polyneuropathy. $\mathcal{F}$ Neurochem 1982;39:1261-5.

12 Mendell JR, Sahenk Z, Whitaker JN, et al. Polyneuropathy and IgM monoclonal gammopathy: studies on the pathogenetic role of anti-myelin-associated glycoprotein antibody. Ann Neurol 1985; 17:243-54.

13 Latov N. Pathogenesis and therapy of neuropathies associated with monoclonal gammopathies. Ann Neurol 1995; 37 (suppl 1):S32-42.

14 Kelly JJ. Peripheral neuropathies associated with monoclonal proteins: a clinical review. Muscle Nerve 1985;8: $138-50$.

15 Bromberg MB, Feldman EL, Albers JW. Chronic inflammatory demyelinating polyradiculoneuropathy: Comparison of patients with and without an associated monoclonal gammopathy. Neurology 1992;42:1157-63.

16 Simmons Z, Albers JW, Bromberg MB, Feldman EL. Presentation and initial clinical course in patients with chronic inflammatory demyelinating polyradiculoneuropathy: comparison of patients without and with monoclonal gammopathy. Neurology 1993;43 2202-9.

17 Simmons Z, Albers JW, Bromberg MB, Feldman EL Long-term follow-up of patients with chronic inflammatory demyelinating polyradiculoneuropathy, without and tory demyelinating polyradiculoneuropathy, without and

18 Trojaborg W, Hays AP, van Der Berg L, Younger DS, Latov N. Motor conduction parameters in neuropathies associated with anti-MAG antibodies and other types of demyelinating and axonal neuropathies. Muscle Nerve demyelinating and

19 Suarez GA, Kelly JJ. Polyneuropathy associated with monoclonal gammopathy of undetermined significance: further evidence that IgM-MGUS neuropathies are differen than IgG-MGUS. Neurology 1993;43:1304-8.

20 Barohn RJ, Kissel JT, Warnolts JR, Mendell JR. Chronic inflammatory demyelinating polyradiculoneuropathy Arch Neurol 1989;46:878-84.

21 Dyck PJ, Lais AC, Otha M, Bastron JA, Okazaki H, Groover RV. Chronic inflammatory polyradiculoneuropathy. Mayo Clin Proc 1975;50:621-37.

22 McCombe PA, Pollard JD, McLeod JG. Chronic inflammatory demyelinating polyradiculoneuropathy. A clinical and electrophysiological study of 92 cases. Brain 1987; 110:1617-30.

23 Albers JW, Kelly JJ. Acquired inflammatory demyelinated polyneuropathies: clinical and electrophysiological feapolyneuropathies: clinical and electro
tures. Muscle Nerve 1989;12:435-51.

24 Bouche P, Moulonguet A, Ben Younes-Chennoufi A, et al. Multifocal motor neuropathy with conduction block: a study of 24 patients. $\mathcal{F}$ Neurol Neurosurg Psychiatry 1995;

25 Kaku DA, England JD, Sumner AJ. Distal accentuation of conduction slowing in polyneuropathy associated with antibodies to myelin-associated glycoprotein and sulphated glucuronyl paragloboside. Brain 1994;117:941-7.

26 Ad hoc subcommittee of the American Academy of Neurology AIDS task force. Research criteria for diagnosis of chronic inflammatory demyelinating polyneuropathy (CIDP). Neurology 1991;41:617-18.

27 Prineas JW, McLeod JG. Chronic relapsing polyneuritis. $f$ Neurol Sci 1976;27:427-58.

28 Azulay J Ph, Pouget J, Pellissier JF, Blin O, Serratrice G. Polyradiculonévrites chroniques: 25 cas. Rev Neurol 1992;148:752-61

29 Dalakas MC, Engel WK. Chronic relapsing (dysimmune) polyneuropathy: pathogenesis and treatment. Ann Neurol polyneuropathy: pathog 30 Hughes RAC. Guillain-Barré syndrome. London: Springer, 
31 Oh SJ, Joy JL, Kuruoglu R. "Chronic sensory demyelinating neuropathy": chronic inflammatory demyelinating polyneuropathy presenting as a pure sensory neuropathy. f Neurol Neurosurg Psychiary 1992;55:677-80.

32 Oh SJ, Joy JL, Sunwoo I, Kuruoglu R. A case of chronic sensory demyelinating neuropathy responding to immunotherapies. Muscle Nerve 1992;15:255-6.

33 Berger AR, Herskovitz S, Kaplan J. Late motor involvement in cases presenting as "chronic sensory demyelinating polyneuropathy". Muscle Nerve 1995;18:440-4.

34 Hughes RAC, Sanders E, Hall S, Atkinson P, Colchester A, Payan P. Subacute idiopathic demyelinating polyradiculoneuropathy. Arch Neurol 1992;49:612-6.

35 Thomas PK, Walker RWK, Rudge P, et al. Chronic demyelinating peripheral neuropathy associated with demyelinating peripheral neuropathy associated with
multifocal central nervous system demyelination. Brain multifocal central

36 Rubin M, Karpati G, Carpenter S. Combined central and peripheral myelinopathy. Neurology 1987;37:1287-90.

37 Hawke SHB, Halliman JM, McLeod JG. Cranial magnetic resonance imaging in chronic demyelinating polyneuropathy. $\mathcal{F}$ Neurol Neurosurg Psychiatry 1990;53:794-6.

38 Ormerod IEC, Waddy HM, Kermode AG, Murray NMF Thomas PK. Involvement of the central nervous system in chronic inflammatory demyelinating polyneuropathy: a clinical, electrophysiological and magnetic resonance imaging study. F Neurol Neurosurg Psychiatry 1990;53: $789-93$.

39 Feasby TE, Hahn AF, Koopman WJ, Lee DH. Central lesions in chronic inflammatory demyelinating polyneuropathy. Neurology 1990;40:476-8.

40 Mendell JR, Kolin S, Kissel JT, Weiss KL, Chakeres DW, Rammohan KW. Evidence for central nervous system demyelination in chronic inflammatory demyelinating polyradiculoneuropathy. Neurology 1987;37:1291-4.

41 Bromberg MB. Comparison of electrodiagnostic criteria for primary demyelinating in chronic polyneuropathy. Muscle Nerve 1991;14:968-76.

42 Uncini A, Di Muzio A, Sabatelli M, Magi S, Tonali P, Gambi P. Sensitivity and specificity of diagnostic criteria for conduction block in chronic inflammatory demyelinating polyneuropathy Electroencephalogr Clin Neurophysiol 1993;89:161-9.

43 Kelly JJ. The electrodiagnostic findings in peripheral neuropathy associated with monoclonal gammopathy. Muscle Nerve 1983;6:504-9.

44 Small GA, Lovelace RE. Chronic inflammatory demyelinating polyneuropathy. Semin Neurol 1993;13:305-12.

45 van der Meché FGA, Vermeulen M, Busch HFM. Chronic inflammatory demyelinating polyneuropathy. Conduc-
tion failure before and during immunoglobulin or plasma therapy, Brain 1989;112:1563-71.

46 Lewis RA, Sumner AJ. Electrodiagnostic distinctions between chronic familial and acquired demyelinative neuropathies. Neurology 1982;32:592-6.

47 Nobile-Orazo E, Monfredi E, Carpo M, et al. Frequency and chemical correlates of anti-neural IgM antibodies in neuropathy associated with IgM monoclonal gammopathy. Ann Neurol 1994;36:416-24.

$48 \mathrm{Kelly} \mathrm{J}$. The electrodiagnostic findings in polyneuropathies associated with IgM monoclonal gammopathies. Muscle Nerve 1990;13:1113-7.

49 Smith IS. The natural history of chronic demyelinating neuropathy associated with benign IgM paraproteinaemia. A clinical and neurophysiological study. Brain 1994;117:949-57. 